\title{
Sedimentation Processes in the Black Sea during the Last Glacial Period Deduced from Grain Size Analyses on Gravity Core MSM 33/54-3 from the Eastern Anatolian Continental Margin
}

\author{
By Carolin Neugebauer
}

\begin{abstract}
Abrupt climate fluctuations within the last glacial period are recorded in several palaeoclimate archives such as Greenland ice cores and northern hemisphere sediments, both marine and terrestrial. Characterised by an abrupt warming within a few decades and followed by gradual cooling, these events - known as Dansgaard-Oeschger events (DO) - are directly related to changes in the sedimentary mechanisms for several marginal basins. Black Sea sedimentary mechanisms were mainly influenced by continental ice sheet dynamics of the northern hemisphere. Variabilities of more intense (stadial) and less intense (interstadial) glacial conditions are caused by variations in North Atlantic oceanic meridional heat transport, leading to regional climate changes (Henry et al. 2016). Thus, changes of regional climate are reflected in the grain size composition of terrestrial and marine sediments. South eastern Black Sea sediments represent well archived paleoenvironmental records of the last glacial course. As a marginal basin with its only connection to the world ocean circulation system via the Bosporus, the Black Sea experienced several periods as an isolated glacial lake, caused by sea level fall during cold DO events. To reveal the dominant modes of temperature variability between 60-30 thousand years, a sedimentary sequence of a gravity core of the south eastern Archangelsky Ridge (41 ${ }^{\circ} 58.985^{\prime} N, 36^{\circ} 43.845^{\prime}$ E) is analysed with respect to several climate indicators. Laser diffractometry and statistical calculation programmes such as GRADISTAT obtained sedimentary parameters in order to estimate the dynamic and genetic reasons for the presence of numerous grain size distributions of the sediments. The process of End-member modelling has been used to assign the grain size distributions to the sedimentary mechanisms during DO events. Additionally, XRF analysis revealed the aeolian and fluviatile indicative elements of the core sequence to clarify how the regional ecosystem, especially vegetation, responded to these climate changes. As a result, the grain size distributions correspond notably with climate changes and therefore, reveal high impacts of DO events on sedimentary processes in the south eastern Black Sea region. The present study contributes a piece to the puzzle of the climate development of Southeast Europe to understand past climate mechanisms as well as to predict future climate scenarios.
\end{abstract}

Keywords: Black Sea, Dansgaard-Oeschger Events, Grain Size Analysis, Palaeoclimate.

\section{Introduction}

Greenland ice core records were first to show that rapid climate fluctuations during Marine Isotope Stage 3 (MIS 3, 59-29 ka years BP) impacted the North Atlantic territory during the last glacial course. These climate fluctuations are

*Master of Science, Germany. 
known as Dansgaard-Oeschger events (DO), characterised by rapid warming over Greenland of as much as $10^{\circ} \mathrm{C}$ within a few decades and followed by a gradual cooling continuing for several centuries, then rapidly leading to stadial conditions (Rahmstorf 2002). Heinrich events (HE) are a climatic phenomenon that occurred during the coldest phases of DO events (Clement and Peterson 2006) and are related to massive episodic iceberg discharges from the Laurentide ice sheet (Rahmstorf 2002). They are reflected as coarse-grained layers in North Atlantic sediments; the thickness of these sediments decreases from several metres in the western Atlantic down to a few centimetres in the eastern Atlantic (Rahmstorf 2002). HE and DO events are not unrelated as Heinrich events are followed by a warm DO event, and DO events tend to get cooler until the next Heinrich event (Rahmstorf 2002). Much remains unknown about the mechanisms that lead to these climate changes. However, changes in the North Atlantic Meridional heat transport caused by freshwater release seem to be one of the main mechanisms that triggered these climate events as sea surface temperatures (SST) of the North Atlantic are closely matched with DO events in Greenland (Clement and Peterson 2006). With respect to that theory, stadial conditions are associated with weak oceanic heat transport and large sea ice extent of northern latitudes. Interstadial conditions are related to strong oceanic heat transport that extends far into the high latitudes of the North Atlantic (Wegwerth et al. 2015). The deep-water formation in the North Atlantic linked to the Atlantic Meridional Overturning Circulation may play a crucial role in triggering climate changes. Three modes of North Atlantic Ocean circulation have been estimated for the last glacial period (Rahmstorf 2002). Based on their occurrence during stadial, interstadial phases and Heinrich events, the modes are stadial mode, interstadial mode and Heinrich mode with reference to Rahmstorf (2002). These modes differ in their location of North Atlantic Deep Water formation and are all but stopped during Heinrich events (Rahmstorf 2002). The cold stadial mode is characterised by reduced deep water formation south of Iceland, during interstadial mode deep water formation increased and experienced a northward shifting into the Nordic Seas (Rahmstorf 2002). Furthermore, a strong ocean circulation led to warmer conditions in the Atlantic, melting ice sheets and freshwater supply into the North Atlantic that weakened the circulation again. Other studies suggest the collapse of northern Laurentide ice sheet, leading to increasing icebergs in the North Atlantic (Heinrich events) and thus, enhanced freshwater supply (Rahmstorf 2002). Probably, it is the interaction of all these mechanisms that may explain the abrupt climate changes during MIS 3.

The NAO (North Atlantic Oscillation) play a key role for the atmospheric and oceanic circulation pattern in the northern hemisphere and represents an index between high-pressure and low-pressure systems of the Atlantic. There are two states of the NAO: a positive NAO intensifies atmospheric circulation caused by strong subpolar low and subtropical high systems of the Atlantic Ocean, strengthening the westerlies between $45-60^{\circ} \mathrm{N}$ (Voelker 1999). Temperatures are increasing in northern Europe but decreasing in the Mediterranean, leading to dry winters in southern Europe (Voelker 1999) and bringing cold air to the 
Black Sea (Hurrel et al. 2003). On the other hand, a negative NAO results in weakened westerlies, so that easterly and meridional wind systems predominate, leading to colder temperatures in northern Europe; southern Europe and the Black Sea experience warmer and humid conditions (Voelker 1999). However, changes in the NAO have an impact on atmospheric pattern and North Atlantic current systems (Dickson et al. 1996), such as of deep water formation and thus, may have contributed to DO events.

No less important is the question whether these events are a phenomenon of the northern hemisphere or whether they appeared with the same dramatic character globally. Recent studies demonstrate that these events are not local to Greenland (Voelker et al. 2002). These events show detectable patterns in many sediments worldwide (Figure 1). Climate fluctuations have also been detected in glacial loess deposits in China. Coarse-grained layers of loess deposits indicate cold climate intervals and are mixed with clay-rich finegrained layers, indicating warm climate intervals (Ruddiman 2008). To identify DO events in sediments, climate fluctuations are traced by means of grain size analysis and linked to sedimentary mechanisms. Local changes in environmental conditions have a direct influence on sediment composition and grain size and actually reflect the contrast between DO stadials and DO interstadials. There are clear indications that dry and cold environmental conditions lead to high proportions of coarse aeolian fractions within a sediment (Ruddiman 2008). On the other hand, warm and humid environmental conditions increase the finegrained fluviatile character of a sediment. These environmental conditions are dependent on prevailing wind systems and local rain fall that were intensified or limited regionally as a result of the impact of DO events.

Figure 1. Global DO Interstadial (left) and Stadial (right) Pattern
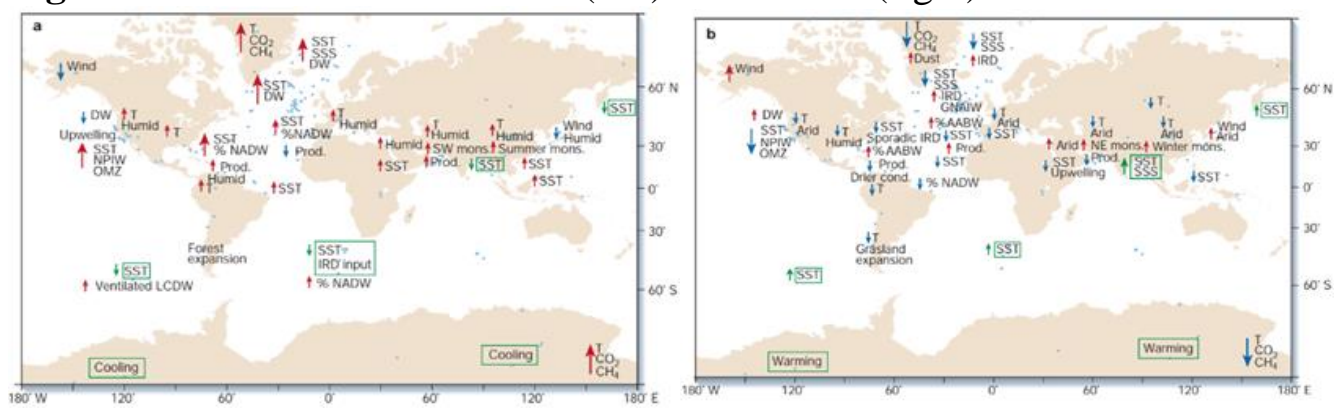

Source: Voelker et al. 2002.

The present paper aims to understand the long-range impact of North Atlantic temperature changes during DO events and the influences on sedimentation mechanisms for the study region to be demonstrated for the period between 60-30 ka years of MIS 3 by detailed grain size analyses. This study is crucial for the assessment of current and future climate changes, as global climate patterns have different regional effects whose intensities cannot yet been estimated. 


\section{Palaeoclimate Black Sea}

As a marginal basin in the middle of the Eurasian continent, the Black Sea reacts very sensitively to environmental and climatic changes in the surrounding area. During the past 670,000 years, the Black Sea experienced several oscillations between brackish and limnic conditions due to sea level fluctuations which have been characterised by the constant change of interruption and connection with the Marmara Sea (Wegwerth et al. 2015). The isolated Black Sea developed to a Black Sea "Lake" during low sea level as saltwater inflows from the Marmara Sea were interrupted and both hydrological and sedimentary conditions were impacted by freshwater fluxes from the Eurasian continent in the north and the Anatolian region in the south. During MIS 3 the sea level of the Black Sea was constantly below present Bosporus sill, indicating the glacial phase of the Black Sea "Lake."

The intensity of freshwater fluxes is directly linked to the extent of the northern hemispheric ice sheets and the associated northward or southward shifted polar front. During the last glacial period the Fennoscandian ice sheet changed its extent remarkable with response to DO warming or cooling. A direct correlation with the dynamics of intermediate ice sheets is assumed, because almost all DO events occurred during past glacial periods (Rahmstorf 2002). Changes of enhanced or weakened westerly winds and fluctuations in precipitation resulted in dramatic environmental changes that can be detected in the sediments of the Black Sea.

Detailed pollen analyses of previous studies allow regional changes in vegetation in northern Anatolia to be correlated with climatic fluctuations (Shumilovskikh et al. 2014). DO interstadials are related to temperate forests due to the onset of humid conditions in northern Anatolia. On the other hand, Black Sea sediments demonstrate non-arboreal pollen during cold DO events and suggest mainly xerophytic biomes that characterised the northern Anatolian region due to arid conditions (Shumilovskikh et al. 2014). Black Sea surface temperatures reacted sensitively to North Atlantic Heinrich events as temperatures cooled down on $3^{\circ} \mathrm{C}$ (Wegwerth et al. 2015).

\section{The Study Region}

The Black Sea is the largest anoxic basin on earth with a characteristic stratification of the water column and a maximum water depth of $2258 \mathrm{~m}$. The upper 100-150 m comprise a freshwater layer that is well-oxygenated, followed by a saline water column below that has anoxic conditions (Kwiecien et al. 2009). This stratification is due to the interruption of vertical circulation caused by the freshwater input of rivers and precipitation and the influx of saline marine water from the Marmara Sea through the Bosporus that is 35 meters below sea level (Kwiecien 2009).

European largest rivers drain into the Black Sea such as the Danube and Dnieper, contributing to the positive water balance by enhanced freshwater 
supply that is higher than evaporation (Wegwerth et al. 2015). Large quantities of sediments ( $>33 \%$ ) are supplied by the large Anatolian rivers such as Kizilirmak into the south eastern Black Sea (Lericolais 2013).

The basin is surrounded by the Carpathian mountains in the west, the Pontic mountains in the south and the Caucasus in the east (Wegwerth et al. 2015).

\section{Local Climate}

The climatic conditions of the Black Sea are influenced by Europe's atmospheric circulation pattern. Main features are the westerlies, the Siberian and mid-latitude subtropical high-pressure systems as well as the Polar Front Jet and the Subtropical Jet (Wegwerth et al. 2015). Indian monsoon and Siberian high-pressure system strongly influence Mediterranean low-pressure systems that reach the Black Sea, depending on the seasonal situation of the Polar Front and Subtropical Jet (Wegwerth et al. 2015). However, the southern Black Sea region is mainly characterised by the Mediterranean climate leading to hot and dry summers and cold and wet winters. Accordingly, a positive winter NAO caused strengthened westerlies and cold and dry air is controlling the Black Sea area. A weakened NAO is leading to south westerlies and wet winters (Wegwerth et al. 2015). During summer the eastern Black Sea and north Anatolia are the most rain-laden regions due to precipitation in the Pontic mountains and Caucasus in the east (Wegwerth et al. 2015). It is precisely this climatic situation of the Black Sea that suggests regional changes in these atmospheric patterns during DO events as the change of one of these features results in the change of the other features as well (Figure 2).

Figure 2. Atmospheric Pattern for the Black Sea Region

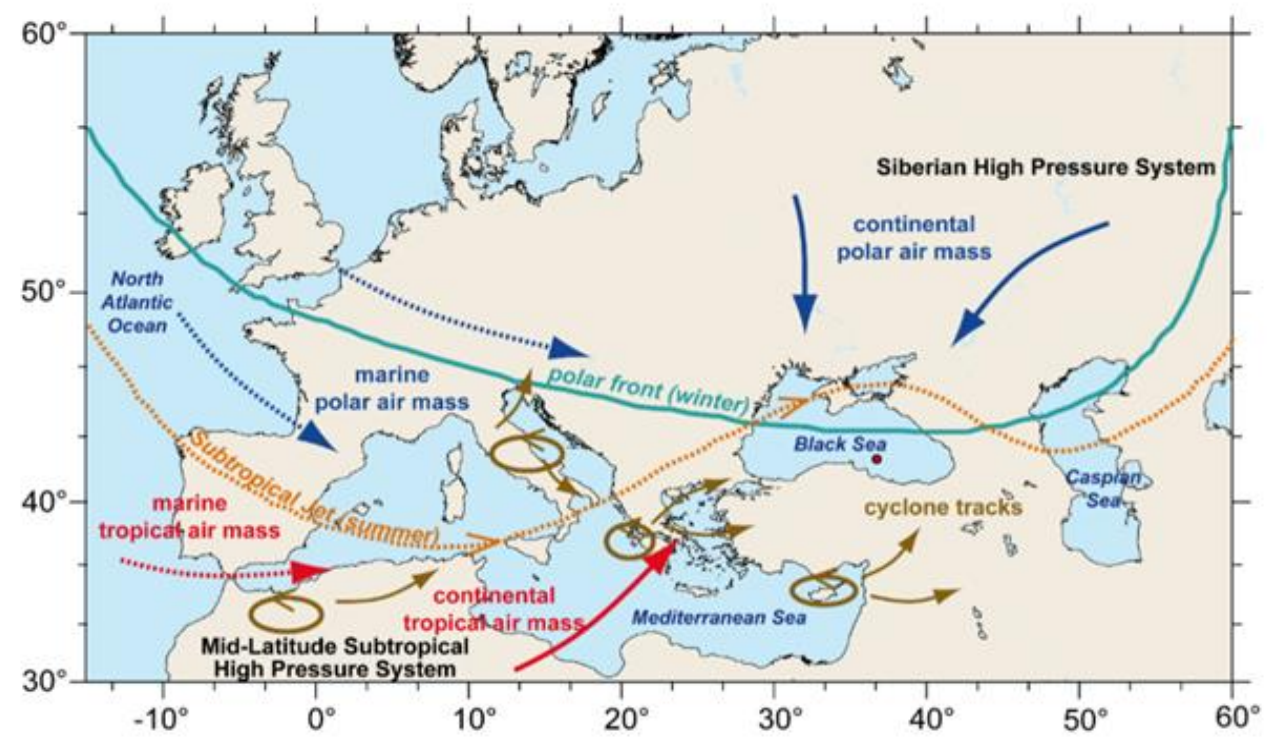

Source: Wegwerth et al. 2016. 


\section{Methods}

\section{Core Sediments}

In order to reconstruct the environmental changes and the associated different sedimentary composition of the Black Sea, a sediment sequence of a gravity core from Archangelsky Ridge $\left(41^{\circ} 58.985^{\prime} \mathrm{N}, 36^{\circ} 43.845^{\prime} \mathrm{E}\right)$ at a water depth of $382.2 \mathrm{~m}$ was examined for its grain size and element composition. The Archangelsky Ridge is an uplifted fault feature of the south eastern Black Sea and located within a highly tectonically active zone of the Anatolian continental margin (Wegwerth et al. 2015). The basin itself represents a part of the ParaTethys that developed as a back-arc basin (Wegwerth et al. 2015).

Black Sea sediments contain three stratigraphic units (Unit I-III) as described by Ross (Ross et al. 1974), comprising mainly coccolith ooze (Unit I), Holocene sapropel (Unit II) and limnic clays of Unit III (Figure 3). The investigated core sequence of $353-552 \mathrm{~cm}$ can be assigned to the clayey sediments of Unit III, covering a time period between 60-30 ka years. Sedimentation in the south eastern Black Sea is relatively low compared to the high sedimentation rates of the western Black Sea (Wegwerth et al. 2015). The age model is based on previous investigations by Nowaczyk et al. (2012) by means of AMS 14C (accelerator mass spectroscopy).

Figure 3. Black Sea Sediment Units I-III

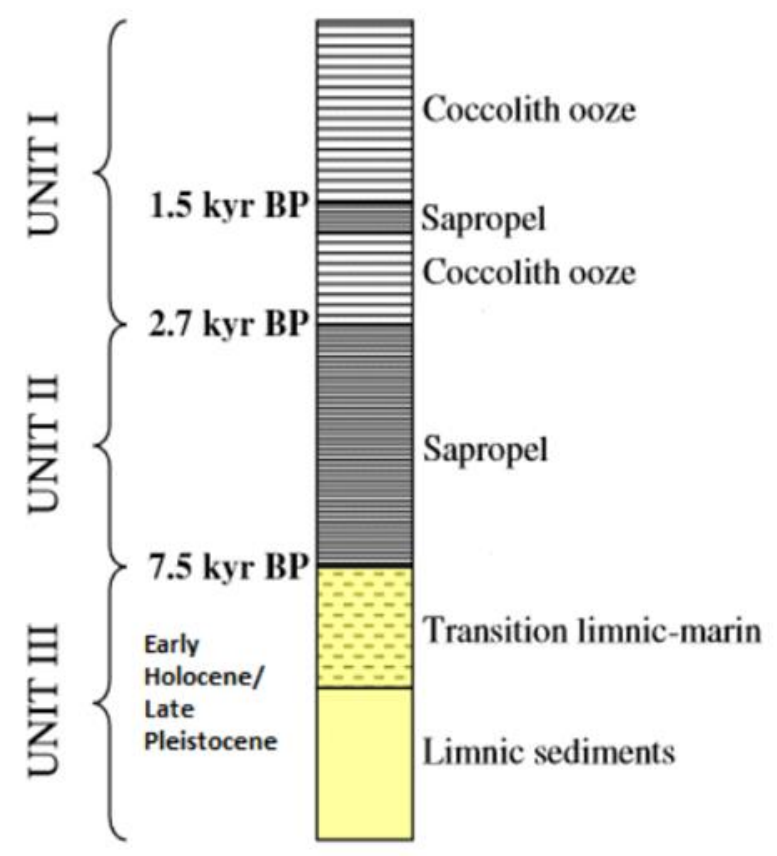

Source: Bahr 2005 (modified by the author). 


\section{Sample Preparation}

First, the core sequence was sub-sampled in $1 \mathrm{~cm}$ units and freeze-dried. Subsequently, a quantity of 120-150 mg sample material was removed. Two sample series were prepared. The laboratory procedure comprised treatment with $15 \mathrm{ml} \mathrm{33 \%} \mathrm{H}_{2} \mathrm{O}_{2}$ for both sample series in order to remove organic particles and the treatment with $15 \mathrm{ml} \mathrm{HCl}$ for the second one for removing calcium carbonate to determine the siliciclastic particles. Both series were heated for $1 \mathrm{~h}$ afterwards. Furthermore, the series were filled with distilled water to keep the particles in suspension and treated with $5 \mathrm{ml}$ dispersed agent and sonicated for 15 minutes. Replicate samples were prepared at intervals of $10 \mathrm{~cm}$, showing a consistent pattern in grain size distribution.

\section{Grain Size Analysis}

Grain size fractions of the core sequence are separated into clay $(<2 \mu \mathrm{m})$, silt $(<2 \mu \mathrm{m}$ to $<62.5 \mu \mathrm{m})$ and sand $(>62.5 \mu \mathrm{m})$. The sediments are classified according to the scale of Udden \& Wenthworth. The grain sizes were analysed by laser diffractometry with the particle size analyser CILAS at the Institute of Baltic Sea Research in Rostock, Warnemünde (IOW). Laser diffractometry is a method based on the principle of light refraction on particles of different sizes, which produces different refraction patterns. As a result, grain sizes were summarised in grain size classes that were used for the statistical calculation program GRADISTAT that was developed by Blott and Pye (2001). It has been written for the grain size analysis with respect to statistics such as mean, mode, sorting and skewness (Blott and Pye 2001).

\section{End-Member Modelling}

The process of End-member modelling has been used to assign the grain size distribution of each sample to sedimentary mechanisms during DO events. Grain size distributions were used as input data from laser particle size analysis for the end-member modelling algorithm. The input data represent reflectance values by means of DRS (Diffuse reflectance spectroscopy) of the grains size distributions (Seidel 2015). The determination of the number of end-members refers to the number of prevailing sedimentation processes and source areas for the studied period as sediments are mainly a mixture of several sedimentation processes (Figure 4). The minimum of end-members is calculated by the coefficient of determination $(r)$ that represents the proportion of variance of grain size classes (Prins and Weltje 1999). 
Figure 4. Number of End-Members by the Coefficient ( $r$ )

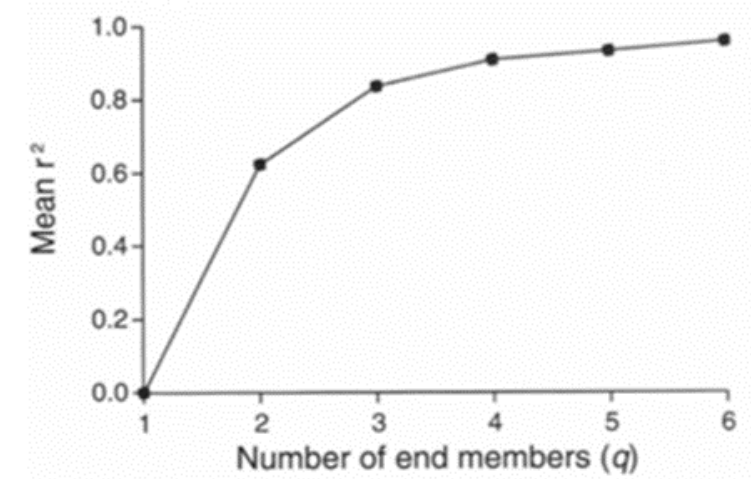

Source: Prins and Weltje 1999.

\section{X-Ray Fluorescence}

High resolution core scanning was carried out by $\mathrm{X}$-ray fluorescence (XRF). XRF was used with respect to the mineral composition of the sediments. In order to exclude dilution effects by carbonate, $\mathrm{Zr}$ was normalised to $\mathrm{Al}$. $\mathrm{Zr}$ is an indicator for aeolian processes and strengthened wind systems and is associated with heavy minerals. $\mathrm{K}$ is mainly due to weathering processes and incorporated into clay minerals, mainly deposited by river influx (Wegwerth et al. 2015).

\section{Results}

\section{Grain Size Results}

The mean varies between $4 \mu \mathrm{m}$ and $8 \mu \mathrm{m}$ and is mainly composed of cohesive fine silt size fractions. Few grains reach $16 \mu \mathrm{m}$ with a trend to the coarser silt fraction. The sorting is classified as poorly sorted with notable shifts for few samples. Poorly sorting is associated with a mixture of several grain size classes. The grain size distribution shows mainly unimodal pattern with except for few samples that show bi- and trimodal pattern, corresponding to coarser grain size due to higher amounts of sand. Coarsening of these samples corresponds to decreased clay content. Grain sizes are increasingly fluctuating between $440 \mathrm{~cm}$ and $550 \mathrm{~cm}$ core depth, indicating changed sedimentation and environmental conditions, respectively.

\section{End-Member Modelling Results}

Three predominantly end members have been obtained as minimum number of end-members for a well approximation of the grain size data. Thus, three main sedimentation mechanisms are assumed. Two end members show a similar trend in grain size classes (EM1, EM2), indicating a similar process or source. End-member 1 and 2 are classified as fine-grained. End-member 3 
comprises the coarse-grained fraction and a wide range of grain size classes. Compared with NGRIP, there are clear inverse reactions between EM1 and EM3. EM1 tends almost towards 0 compared to the maximum values of EM3. EM1 reaches maximum values during DO interstadials, maximum values of EM3 are correlated with DO stadials (Figure 5). For visualisation of the results in Figures 5 and 6, EM 1 was considered, since EM2 comprises the same grain size classes as EM1.

Figures 5 and 6. Results Plotted to NGRIP and $C a X R F$
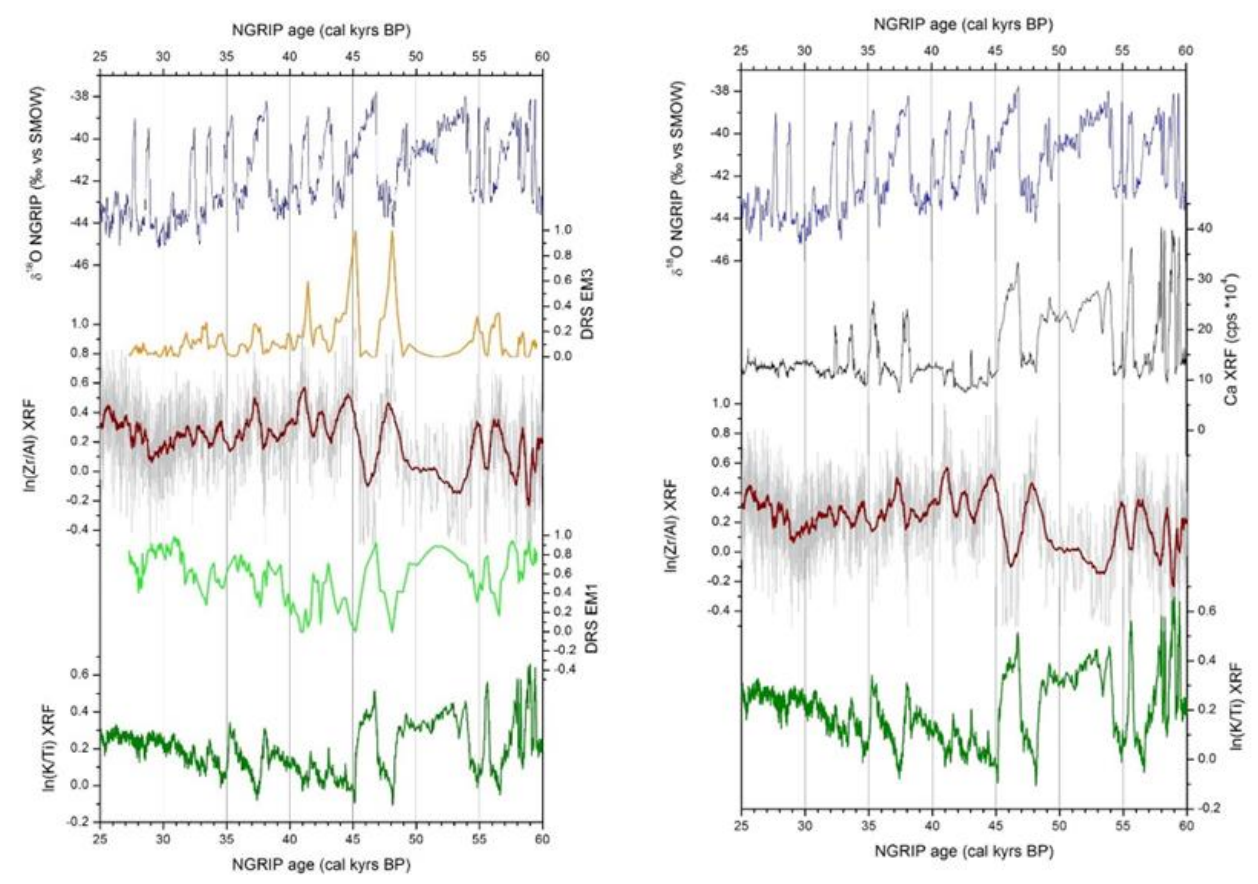

\section{XRF Results}

Ratios of $\ln (\mathrm{Zr} / \mathrm{Al}) \mathrm{XRF}$ and $\ln (\mathrm{K} / \mathrm{Ti}) \mathrm{XRF}$ are compared to NGRIP and the calculated end-members. Maximum peaks of $\ln (\mathrm{Zr} / \mathrm{Al}) \mathrm{XRF}$ correspond to maximum peaks of EM3. Thus, the coarse-grained fraction can be correlated with high $\ln (\mathrm{Zr} / \mathrm{Al}) \mathrm{XRF}$. High $\ln (\mathrm{K} / \mathrm{Ti}) \mathrm{XRF}$ is correlated with maximum values of EM1. Lowering in $\ln (\mathrm{K} / \mathrm{Ti}) \mathrm{XRF}$ results in low EM1 and the fine-grained fraction (Figure 5). A clear inverse reaction between $\ln (\mathrm{Zr} / \mathrm{Al}) \mathrm{XRF}$ and $\ln (\mathrm{K} / \mathrm{Ti})$ $\mathrm{XRF}$ can be derived as well as for EM1 and EM3. Hence, high $\ln (\mathrm{Zr} / \mathrm{Al}) \mathrm{XRF}$ and high EM3 correspond remarkable to cold DO events. These values are almost diminished during DO warming, when $\ln (\mathrm{K} / \mathrm{Ti}) \mathrm{XRF}$ and EM1 are at highest.

Regarding Ca XRF the results correspond with climate changes detected in NGRIP. Increasing temperatures correlate with high amounts of $\mathrm{Ca}$ (Figure 6). Lowering in temperature agree with decreased $\mathrm{Ca}$ XRF. $\mathrm{Ca}$ is mainly originating inorganic due to increasing temperatures that lead to inorganicallyprecipitated carbonates as suggested by Kwiecien et al. (2009). Decreased Ca $\mathrm{XRF}$ is the result of inputs of terrigenous material that leads to carbonate 
dilution (Kwiecien et al. 2009). However, primary productivity in the Black Sea was high during DO interstadials and low during DO stadials.

\section{Discussion}

Because high $\ln (\mathrm{Zr} / \mathrm{Al}) \mathrm{XRF}$ and high EM3 match, it can be concluded that both values indicate the same sedimentary process and source, respectively. The maximum peaks of EM3 remarkable correspond to few samples with maximum shifts in their grain size for 42 ka years, 45 ka years and 47.5 ka years, demonstrating highest contents in coarse grains related to sand. The coarsegrained character of the sediments indicates aeolian supply due to arid conditions of northern Anatolia and low vegetation, raising soil erosion as well as ice-rafted debris as suggested by Shumilovskikh et al. (2014). Low primary productivity and xerophytic vegetation corresponds with these values during DO stadials (Shumilovskikh et al. 2014) and are supported by high Ca XRF results. Related to a southward shifted polar front due to ice sheet extent, European polar air masses and strengthened westerlies gained increased influence on the study region. Accordingly, less Mediterranean cyclones reached the Black Sea basin, thus, evaporation was higher than precipitation and riverine freshwater input (Wegwerth et al. 2015) (Figures 7 and 8). DO stadials mainly experienced strong winters leading to coastal ice formation and thus, explain the amounts of ice-rafted debris in southern Black Sea sediments (Wegwerth et al. 2015). There are no clear differences between HE and normal cooling DO events in the sediments detected, but highest $\ln (\mathrm{Zr} / \mathrm{Al}) \mathrm{XRF}$ and EM3 at 48 ka years may notably correspond to Heinrich event 5 (HE 5). However, ice-rafted debris are not sufficiently proven in the present study. Several studies document large eastern and southeastern loess deposits during cold and dry periods that demonstrate high amounts of $\mathrm{Zr}$ (Buggle et al. 2008). Generally coarsening in grain sizes of loess deposits from Western Europe to the Dnieper valley is observed for $40 \mathrm{ka}$ years BP by Rousseau et al. (2014). These results are similar to the present study as main coarsening of grain sizes occur between 40 ka years and 50 ka years. Rousseau et al. (2014) revealed strengthened North West winds due to northern hemisphere ice sheets. Aeolian deposits are located along rivers such as Danube, acting as source areas for sediment supply by wind systems when river flow was low (Rousseau et al. 2014). Thus, both the north of the Black Sea and Anatolia offer sources for aeolian sedimentation.

On the other hand, high $\ln (\mathrm{K} / \mathrm{Ti}) \mathrm{XRF}$ corresponds with high EM1, indicating fine-grained sediments that suggest freshwater supply of rivers and may be related to enhanced riverine inflows by the Kizilirmak as well. Increased fluviatile supply may reflect melting ice in the Anatolian mountains but also of the Fennoscandian ice sheet as well as increased precipitation (Wegwerth et al. 2015). Spread of temperate and grassland biomes at 54-45 ka and 28-20 ka BP suggest humid conditions and correspond to high concentrations of freshwater and brackish dinocysts, indicating high productivity during DO interstadials as established by Shumilovskikh et al. (2014). At 54-45 ka BP, high EM1 and K are 
considerably constant on the expense of EM3 and Zr, supporting the idea of warm and humid conditions for this interval and increased riverine input (Figure 5). Studies by Voelker et al. are in accordance with these results (Voelker et al. 2002) (Figure 1). Furthermore, increased fluviatile input corresponds with minimum ice extent of the Fennoscandian ice sheet (Wegwerth et al. 2015). More Mediterranean cyclones reached the Black Sea basin due to a northward shifted polar front and weakened westerlies, thus, leading to higher precipitation than evaporation for the Black Sea (Wegwerth et al. 2015) (Figures 9 and 10). Shumilovskikh et al. (2014) estimated freshening of the Black Sea surface caused by humid conditions.

However, the grain size distribution is a result of the interaction of various parameters such as changes in wind strength, sea level and local precipitation. These parameters changed in accordance with DO patterns. Glaciated Anatolian mountains may contribute to diminished freshwater supply into the southern Black Sea during DO stadials and vice versa. Pollen analysis by Shumilovskikh et al. (2014) indicates temperate and warm-temperate aboreal pollen that suggest glacial refugia in northern Anatolia. Much remains still unknown about the glaciation history of northern Anatolian mountains and its effects on sedimentation processes. Further, it is of interest to find out from where the aeolian entries come. Sources are both the European loess in the north and northern Anatolia in the south of the Black Sea. Previous studies by Wegwerth et al. (2015) have suggested aeolian indicators by the analysis of n-alkanes in the sediments, as n-alkanes represent leaf wax lipids from higher vasculant plants (Wegwerth et al. 2015). High n-alkanes indicate less vegetation cover of the source area and strengthened wind systems during cold intervals. With respect to studies by Shumilovskikh et al. (2014) these n-alkanes have their source in northern Anatolia, suggesting aeolian inputs from the south of the Black Sea.

Figures 7 and 8. Environmental Conditions of the Black Sea during DO Stadials

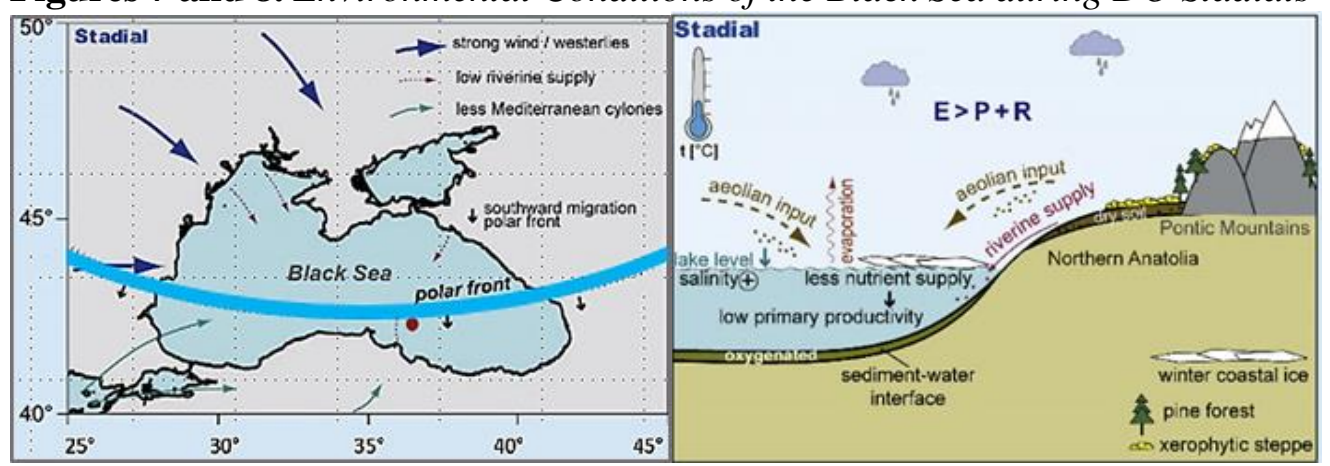

Source: Wegwerth et al. 2016 (modified by the author). 
Figures 9 and 10. Environmental Conditions of the Black Sea during DO Interstadials

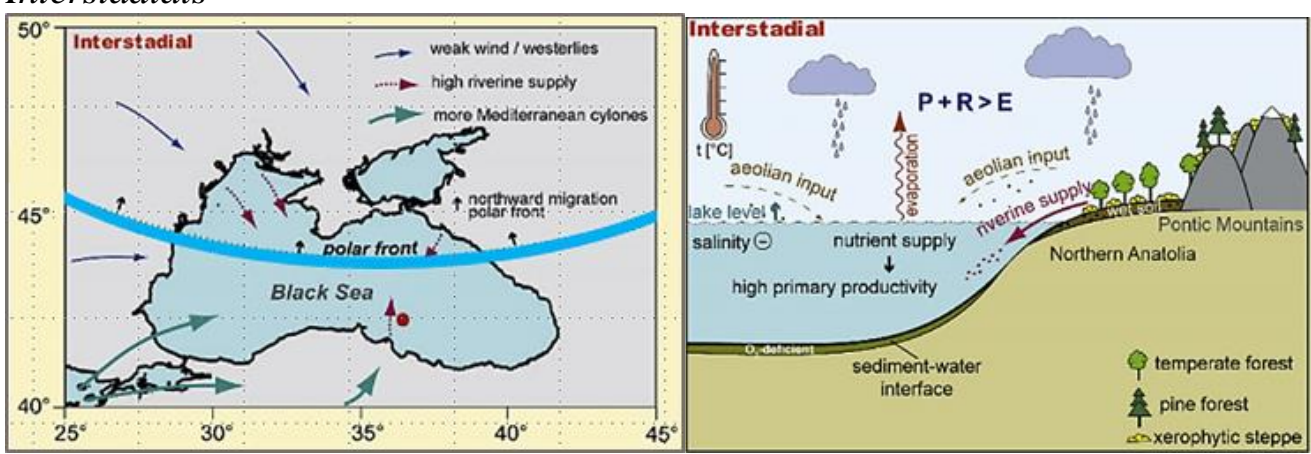

Source: Wegwerth et al. 2016 (modified by the author).

\section{Conclusions}

The present study shows clear patterns of DO events during MIS 3 in south eastern Black Sea sediments. The changes between warm and cold DO events indicate remarkable environmental changes for the Black Sea during the last glacial period. The multi-proxy application of sediment core analysis methods by means of grain size analysis, end-member modelling and XRF analysis leads to a clearer picture of the supra regional effects of DO events between 60-30 ka years BP on the Eurasian continent. DO interstadials led to warm and humid conditions with high influences of Mediterranean low-pressure systems and higher precipitation for northern Anatolia, corresponding to a mainly fluviatile character of the sediments due to freshwater inflows. On the other hand, a coarse-grained character of the sediments with aeolian-deposited elements such as $\mathrm{Zr}$ reflect cold and arid conditions of the environment during DO stadials due to enhanced wind systems and less vegetation cover in northern Anatolia. Thus, DO events had similar effects on inland areas as for the North Atlantic region, as previous studies by Wegwerth et al. (2015) and Voelker et al. (2002) suggested. These effects are due to changing ice sheet extents of the northern hemisphere as well as northern oceanic circulation changes and varying modes of the NAO that can be both the mechanism and consequence of DO events. This question remains still open. However, many studies are necessary to analyse past climate processes for marginal basins as they offer perfect palaeoclimate archives that may explain future climate changes for both global and regional areas as well.

\section{References}

Bahr A (2005) Late Glacial to Holocene Paleoenvironmental Evolution of the Black Sea. Dissertation. Bremen.

Blott SJ, Pye K (2001) Gradistat: A Grain Size Distribution and Statistics Package for the Analysis of Unconsolidated Sediments. Earth Surface Processes and Landforms 26(11): 1237-1248. 
Buggle B, Glaser B, Zöller L, Hambach U, Marković S, Glaser I, Gerasimenko N (2008) Geochemical Characterization and Origin of Southeastern and Eastern European Loesses (Serbia, Romania, Ukraine). Quaternary Science Reviews 27(9-10): 1058-1075. Doi:10.1016/j.quascirev.2008.01.018.

Clement AC, Peterson LC (2008) Mechanisms of Abrupt Climate Change of the Last Glacial Period. Reviews of Geophysics 46(4): 1-39. Doi:10.1029/2006RG000204.

Dickson RR, Lazier J, Meincke J, Rhines P, Swift J (1996) Long-term Co-ordinated Changes in the Convective Activity of the North Atlantic. Progress in Oceanography 38(3): 241-295.

Henry LG, McManus JF, Curry WB, Roberts NL, Piotrowski AM, Keigwin LD (2016) North Atlantic Ocean Circulation and Abrupt Climate Change during the Last Glaciation. Science 353(6298): 470-474. DOI: 10.1126/science.aaf5529.

Hurrell JW, Kushnir Y, Ottersen G, Visbeck M (2003) An Overview of the North Atlantic Oscillation. In JW Hurrell, Y Kushnir, G Ottersen, M Visbeck (eds), The North Atlantic Oscillation: Climatic Significance and Environmental Impact, Geophysical Monograph 134. Washington DC: American Geophysical Union.

Kwiecien O, Arz HW, Lamy F, Plessen B, Bahr A, Haug GH (2009) North Atlantic Control on Precipitation Pattern in the Eastern Mediterranean/Black Sea Region during the Last Glacial. Quaternary Research 71(3): 375-384.

Lericolais G (2013) Late Quarternary Deep-Sea Sedimentation in the western Black Sea: New Insights from Recent Coring and Seismic Data in the Deep Basin. Global and Planetary Change 103(Apr): 232-247.

Nowaczyk NR, Arz HW, Frank U, Kind J, Plessen B (2012) Dynamics of the Laschamp Geomagnetic Excursion from Black Sea Sediments. Earth and Planetary Science Letters 351-352(Oct): 54-69.

Prins MA, Weltje GJ (1999) End-Member Modeling of Siliciclastic Grain-Size Distributions: The Late Quaternary Record of Eolian and Fluvial Sediment Supply to the Arabian Sea and its Paleoclimate Significance. In J Harbaugh (ed), Numerical Experiments in Stratigraphy Recent Advances in Stratigraphic and Sedimentologic Computer Simulations, SEPM Special Publication 62, 91-111. Society for Sedimentary Geology.

Rahmstorf S (2002) Ocean Circulation and Climate during the Past 120,000 Years. Nature 419(6903): 207-14. Doi:10.1038/nature01090.

Ross DA, Degens ET (1974) Recent Sediments of the Black Sea. In ET Degens, DA Ross (eds), The Black Sea - Geology, Chemistry, and Biology. Tulsa, Oklahoma, U.S.A: American Association of Petroleum Geologists.

Rousseau DD, Chauvel C, Sima A, Hatte C, Lagroix F, Antoine P, Balkanski, Y, Fuchs M, Mellett C, Kageyama M, Ramstein G, Lang A (2014) European Glacial Dust Deposits: Geochemical Constraints on Atmospheric Dust Cycle Modeling. Geophysical Research Letters 41(21): 7666-7674. Doi:10.1002/2014GL061382.

Ruddiman WF (2008) Earth's Climate, Past and Future (Second Edition) New York: WH Freeman.

Seidel M (2015) A R-based Function for Modeling of End Member Compositions. Mathematical Geoscience 47(8): 1-13.

Shumilovskikh LS, Fleitmann D, Nowaczyk N., Behling H, Marret F, Wegwerth A, Arz HW (2014) Orbital- and Millennial-Scale Environmental Changes between 64 and 20 ka BP Recorded in Black Sea Sediments. Climate of the Past 10(3): 939-954.

Voelker, Antje HL (1999) Zur Deutung der Dansgaard-Oeschger-Ereignisse in Ultrahochauflösenden Sedimentprofilen aus dem Europäischen Nordmeer. [DansgaardOeschger Events in Ultra-high Resolution Sediment Records from the Nordic 
Seas] (Dissertation) Kiel: Inst. für Geowissenschaften der Christian-AlbrechtsUniversität.

Voelker, Antje HL (2002) Global Distribution of Centennial-Scale Records for Marine Isotope Stage (MIS) 3: A Database. Quaternary Science Reviews 21(10): 11851214.

Wegwerth A, Ganopolski A, Ménot G, Dellwig O, Kaiser J, Bard E, Lamy F, Arz HW (2015) Black Sea Temperature Response to Glacial Millennial-scale Climate Variability. Geophysical Research Letters 42(19): 8147-8154.

Wegwerth A, Kaiser J, Dellwig O, Shumilovskikh LS, Nowaczyk NR, Arz HW (2016) Northern Hemisphere Climate Control on the Environmental Dynamics in the Glacial Black Sea "Lake” Quaternary Science Reviews 135 (Mar): 41-53. 